\title{
CURRENT STATUS OF RESEARCH PROJECT ACTIVITIES IN MEDICAL UNIVERSITIES IN BULGARIA
}

\author{
Svetoslav Garov ${ }^{1}$, Maria Dencheva ${ }^{2}$, Angelina Kisselova ${ }^{2}$ \\ 1) Department of Health Policy and Management, Faculty of Public Health, \\ Medical University - Sofia, Bulgaria \\ 2) Department of Imaging and Oral Diagnostic, Faculty of Dental Medicine, \\ Medical University - Sofia, Bulgaria
}

\section{ABSTRACT:}

Introduction: In Bulgaria there are five medical universities: in the cities of Sofia, Plovdiv, Varna, Pleven and Stara Zagora. Their main mission is training specialists in the fields of medicine and health care, increasing their qualification by means of postgraduate education and performing research activities. One of medical universities' top priorities is encouraging research activities mainly aimed at preparation and implementation of research projects.

Aim: The purpose of our study is to examine the current status of research project activities in Bulgarian medical universities.

Material and methods: In order to define the science competitions related to Bulgarian medical universities we have applied a documentary and sociological approach.

Results: Research projects that Bulgarian medical universities can apply for are divided into two groups national and international. The most significant international projects are European ones since Bulgaria is an EU member state and this allows us to participate in such projects.

Conclusion: Universities should strive for establishing even better conditions for encouraging application for research projects aimed at developing competent and experienced staff, even though the majority of them may not obtain approval for financing.

The changes in the situation regarding Bulgarian science require the implementation and development of more research staff motivated to improve their knowledge and skills in the relevant dynamically changing competition and project field.

Key words: Bulgarian medical universities, science competitions, research projects, EU member, research project financing.

\section{INTRODUCTION}

In Bulgaria there are five medical universities: in the cities of Sofia, Plovdiv, Varna, Pleven and Stara Zagora. Their main mission is training specialists in the fields of medicine and health care, increasing their qualification by means of postgraduate education and performing research activities. One of medical universities' top priorities is encouraging research activities mainly aimed at preparation and implementation of research projects. Besides lecturing and educational activities they also do research. Major tools used in that kind of activity are research projects.

\section{AIM}

The purpose of our study is to examine the current status of research project activities in Bulgarian medical universities.

\section{MATERIAL AND METHODS}

In order to define the science competitions related to Bulgarian medical universities we have applied a documentary and sociological approach.

\section{RESULTS AND DISCUSSION}

Research projects that Bulgarian medical universities can apply for are divided into two groups national and international. The most significant international projects are European ones since Bulgaria is an EU member state and this allows us to participate in such projects.

Research project financing in medical universities is based on free competition and experts' estimation using professionally selected criteria. It is in full compliance with the requirements of both national and international legislation in this field. 


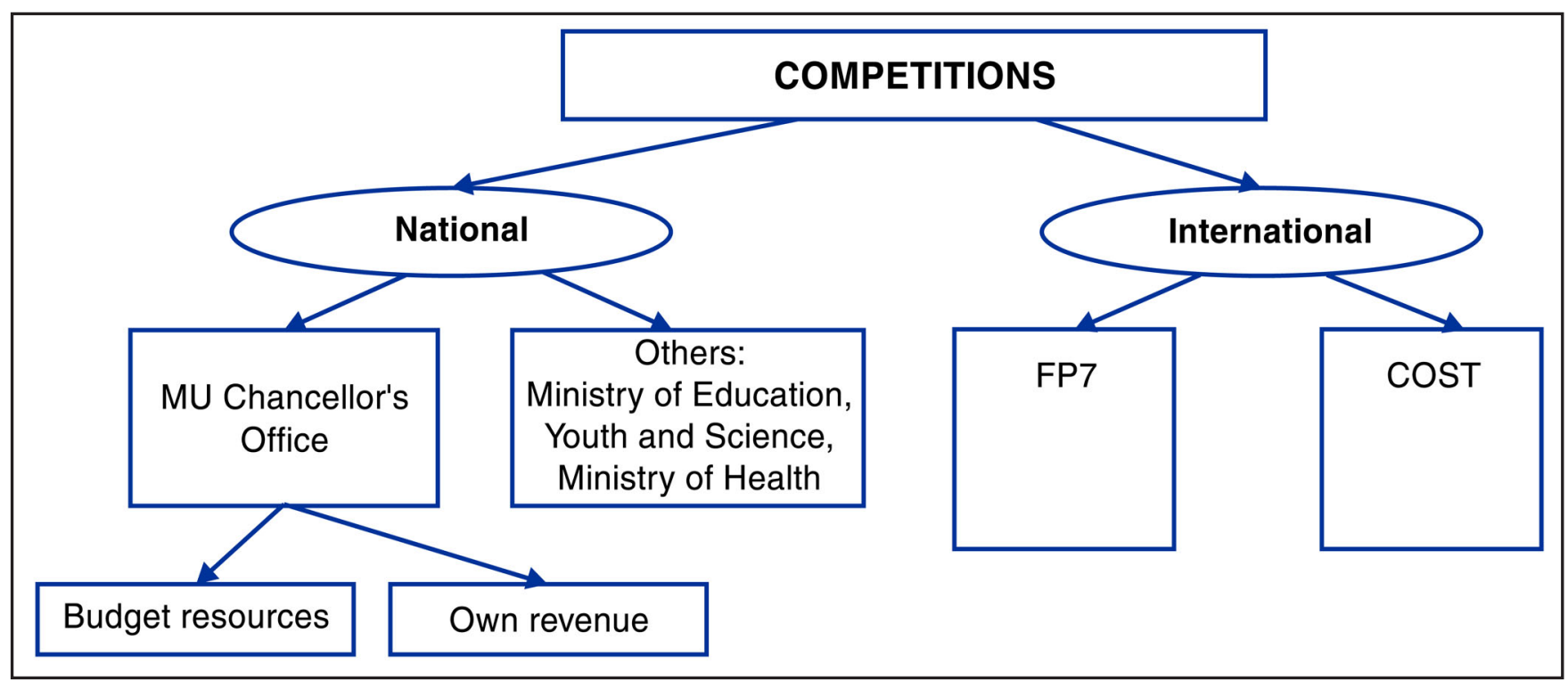

Fig. 1. Science competitions related to Bulgarian medical universities

\section{National research projects}

In order to support and finance the activities performed by research teams at medical universities an objective and scientifically grounded approach has been approved through:

A. Research development estimation made by established for that particular purpose scientific councils having different names at different universities, for example Medical Science Council (MSC) at the Medical University of Sofia; Research Activities Council at the Medical University of Plovdiv, etc.

B. Research Ethics Committee (REC): REC at the Medical University of Sofia; Ethics Committee at the Medical University of Plovdiv; REC at the Medical University of Varna, etc.
National projects in the research field that one can apply for are as follows:

1. Organized at the Chancellor's Office of the relevant medical university

Medical universities announce competitions for financing research projects using budget resources for the relevant year.

Projects are divided according to science trends shown on Fig. 2:

a) medical and biological. i.e. testing various living organisms but not humans;

b) medical and clinical. i.e. including human clinical trials;

c) medical and social.

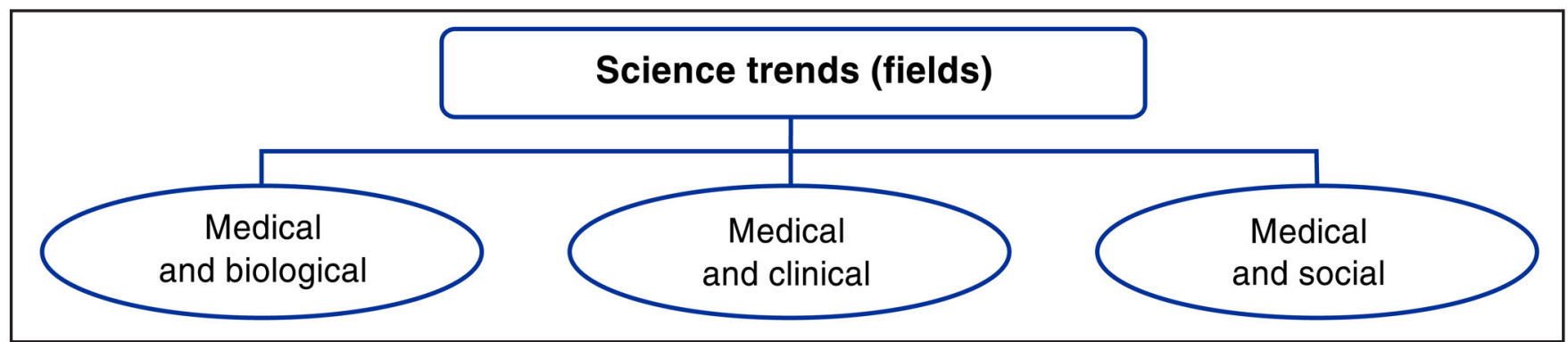

Fig. 2. Medical university science trends

Within the very trends projects are separated into specialties: medicine, pharmacy, dental medicine, etc.

\section{Other projects}

At the Ministry of Education, Youth and Science Bulgarian Science Fund; at the Ministry of Health; Bulgarian
Ministry of Regional Development; the Ministry of Economy and Energy; research projects within the interuniversity cooperation framework financed by the participating medical universities; financed by governmental institutions, laboratories, sponsor companies, foundations, 
natural persons and non-governmental organizations.

a) at the Ministry of Education, Youth and Science

Bulgarian Science Fund was established as a department at the Ministry of Education, Youth and Science in 1990. It is a major national source for financing research using government budget resources. Its establishment was one of the first steps related to the introduction of project financing based on the idea that science is the nation's driving force. Through its financing the Science Research Fund supports the Bulgarian science development and its interaction with other social and economic spheres as well as with the international scientific society based on democracy principles and in compliance with the contemporary trends in our country. [1]

They announce priority field competitions and topics that one can apply for with projects subject to estimation.

The purpose of those competitions is to encourage the performance of high quality and competitive science and applied research in top priority fields.

Total amount of finances for 2013: 19200 000,00

BGN.

\section{- Duration}

Project performance duration: 24 months.

For the purposes of stage separation specified in project proposals the first stage covers 12 (twelve) months as of the date of granting the advance financing. The second stage covers 12 (twelve) months as of the date of granting the finances required for the second stage.

b) at the Ministry of Health

- 2007-2013 Human Resources Development Operational Program projects.

- 2007-2013 Regional Development Operational Program projects.

\section{- HIV/AIDS programs [4]}

II. Research projects as part of international programs (European programs)

\section{Seventh Framework Program}

EU Seventh Framework Program (FP7) for research, technological development and demonstration activities covering the period between 2007 and 2013 is meant to support the creation of an integrated European Research Area (ERA) aimed at achieving long-term and sustainable economic growth. Its major goal is to encourage innovations in science. Its budget financing is quite significant - 8.1 billion Euro for 2012. [5]

The program supports the performance of top science research in newly arising fields of knowledge. It encourages the best science teams to carry out joint research in contemporary trends. It actively supports the creation of a new generation of talented young scientists who are to remain in Europe and go for achieving a competitive economy based on knowledge and skills. It encourages the integration of the science policy with the other policies of the Community, i.e. employment, regional development, competitiveness and innovations, in order to guarantee their complementation and successful interaction.

The Framework program national coordinator for Bulgaria is the Ministry of Education and Science.

The Seventh Framework Program is implemented through four large scale programs: Cooperation, Ideas, People and Capacities.

Horizon 2020 Program is going to be implemented during the next program period and it will be aimed at uniting the currently existing three separate EC programs/initiatives: Science, Innovations and the Seventh Framework Program. The total amount of financing planned for 2014-2020 is 80 billion Euro. The program will focus on turning the revolutionary achievements in the field of science into innovative products and services that are to ensure opportunities for development of universities within the Community, of research organizations and businesses and to improve people's lives. At the same time it will be aimed at drastic reduction of bureaucracy by simplifying the regulations and procedures for employing the best research workers and attracting a larger circle of innovative businesses. [2]

\section{COST program}

COST Program was started in 1971 and it is an intergovernmental framework for European cooperation in the fields of scientific and technical research providing European level coordination of research activities finance by individual states. [3]

Application procedure: Each COST Action is a joint research activity in the form of a project based on the Memorandum of Understanding. This Memorandum has to be signed by the governments of the countries willing to participate in the program.

In order for one COST Action to be proposed at least 5 countries have to sign the so called Memorandum of Understanding, which is considered as the legal grounds for this project. It specifies the common goals, the types of activities to be performed, the conditions for participation and, if necessary, the intellectual property rights. The Science Research Fund at the Ministry of Education, Youth and Science has been selected as the national coordinator for participation in this program.

\section{CONCLUSION}

Research project financing is made with the idea of creating social benefits, i.e. social welfare is a supreme goal.

Universities should strive for establishing even better conditions for encouraging application for research projects aimed at developing competent and experienced staff, even though the majority of them may not obtain approval for financing.

This summary covers the most significant research 
programs related to medical universities in Bulgaria. The changes in the situation regarding Bulgarian science require the implementation and development of more research staff motivated to improve their knowledge and skills in the relevant dynamically changing competition and project field.

\section{REFERENCES:}

1. Bulgarian Science Fund, http:// www.bulfund.com/

2. Horizon 2020 - European Commission, http://ec.europa.eu/ research/horizon2020/index_en.cfm

3. National Cost Coordination
Office - Bulgaria, http:// c o s t.g a t e w a y. b g / page.php? category $=64$

4. Program - Prevention and control of HIF/AIDS, Ministry of
Health, http://www.aidsprogram.bg/ index.php?lang $1=$ en

5. Seventh Framework Program (FP7), http://cordis.europa.eu/ fetch?CALLER=FP7_NEWS

Address for correspondence:

Dr. Svetoslav Garov,

Department of Health Policy and Management, Faculty of Public Health, Medical University - Sofia

8, Bialo more str., 1527, Sofia, Bulgaria

E-mail:sv.garov@gmail.com 